\title{
Electrocardiographic profile of patients with hypertensive disorders in pregnancy
}

\author{
Devika Desai, Madhva Prasad S.*
}

Department of Obstetrics and Gynecology, Seth GS Medical College and KEM Hospital, Mumbai, Maharashtra, India

Received: 08 April 2017

Accepted: 02 May 2017

\section{*Correspondence:}

Dr. Madhva Prasad S.,

E-mail: madhva@gmail.com

Copyright: (c) the author(s), publisher and licensee Medip Academy. This is an open-access article distributed under the terms of the Creative Commons Attribution Non-Commercial License, which permits unrestricted non-commercial use, distribution, and reproduction in any medium, provided the original work is properly cited.

\begin{abstract}
Background: Preeclampsia in pregnancy is a frequently encountered entity. Recent evidence suggests that preeclampsia can be considered as a screening test for future cardiovascular problems and abnormalities in pregnancy may help in counselling patients regarding future risk of cardiovascular problems. Electrocardiography (ECG) is a simple tool for detecting cardiovascular problems. While physiological changes in the ECG in pregnancy have been documented, the pattern of ECG in hypertensive disorders of pregnancy is not adequately studied in India. This formed the basis of the study.

Methods: 140 patients who have been diagnosed as gestational hypertension and pre-eclampsia during the pregnancy were studied in the antenatal period. An ECG (non-portable, standard, 12 lead) available in the hospital was done, and the ECG was reported by the physician on-call.

Results: The average age distribution of the patients was 28.26 years. Majority of the patients in the study were primigravidae. $35 \%$ of the patients were more than 37 weeks of gestation. 20 patients showed electrocardiographic abnormalities. The most common abnormality was sinus tachycardia and left axis deviation.

Conclusions: ECG abnormalities are seen in $14.2 \%$ of preeclamptic women. ECG abnormalities in preeclamptic women studied had no relation to the maternal age, gestational age; parity and use of antihypertensives.
\end{abstract}

Keywords: Electrocardiography, Hypertension, Preeclampsia

\section{INTRODUCTION}

The leading cause of mortality among women continues to be cardiovascular disease among women which include ischemic heart disease, stroke and related issues. Preeclampsia in pregnancy is a frequently encountered entity. ${ }^{1}$ Recent evidence suggests that preeclampsia can be considered as a screening test for future cardiovascular problems and abnormalities in pregnancy may help in counselling patients regarding future risk of cardiovascular problems. Electrocardiography (ECG) is a simple tool for detecting cardiovascular problems. While physiological changes in the ECG in pregnancy have been documented, the pattern of ECG in hypertensive disorders of pregnancy is not adequately studied in India. This formed the basis of the study.

\section{METHODS}

The study was done on patients admitted to the department of obstetrics and gynecology in a public hospital based in urban India. It was performed after institutional ethics committee clearance. Patients who have been diagnosed as gestational hypertension and preeclampsia during the pregnancy were studied in the antenatal period. Routine management of antenatal/medical problems and labor/delivery was continued by the treating obstetrician unit under which she was admitted. Exclusion criteria were assessed. 
Those with known hypertension prior to pregnancy, a diagnosed heart disease, systemic illnesses, and those requiring ICU admission due to any reason were excluded from the study. Consent was obtained and relevant data including age, parity index, previous obstetric history, medical high risks was noted.

An ECG (non-portable, standard, 12 lead) available in the hospital was done. For performance of ECG, the patient was accompanied on a wheel chair. The ECG so obtained was reported by the physician on-call. If any abnormality was reported, and if any specific advice was given, it was followed. The report (normality or abnormality, if any) was noted. If ECG changes were present, advice of a cardiologist was sought and any further management was done. Those who had ECG changes were counselled regarding future risk of cardiovascular problems, based on available medical literature.

\section{Statistical analysis}

The distribution of the basic parameters of the patients were calculated as simple percentages and represented graphically as tables, pie charts or bar diagrams. The various parameters of the patients studied (maternal age, gestational age, parity, use of antihypertensive) were tabulated against presence or absence of ECG changes into two by two columns. Fischer's exact test was applied and p-value was calculated to look for statistical significance.

\section{RESULTS}

The baseline characteristics of the patients who were included are shown below. The average age distribution of the patients was 28.26 years. As shown in Table 1, majority of the patients in the study were primigravidae.

Table 1: The distribution of patients based on parity index.

\begin{tabular}{|lll|}
\hline Parity & Number $(\mathbf{n = 1 4 0})$ & $\%$ \\
\hline Primigravidae & 72 & 51.4 \\
\hline G2 & 25 & 17.8 \\
\hline G3 & 24 & 17.1 \\
\hline G4 and above & 19 & 13.5 \\
\hline
\end{tabular}

As shown in Figure 1, 35\% of the patients were more than 37 weeks of gestation. Approximately 34\% belonged to the more than 32 weeks below 37 weeks group.

As shown in Table 2, majority of the patients were on a single antihypertensive agent at the time of study. 73 patients were on labetalol, 5 were on nifedipine and 33 were on multiple antihypertensives. 29 patients were on no antihypertensives. As shown in Figure 2, most of the patients who were studied had been taking antihypertensives for duration of less than 1 week.
Table 2: The distribution of patients based on the number of anti-hypertensives each patient was on.

\begin{tabular}{|lll|}
\hline No. of antihypertensives & $\begin{array}{l}\text { No. of patients } \\
(\mathbf{n}=\mathbf{1 4 0})\end{array}$ & $\%$ \\
\hline 0 (No antihypertensive) & 29 & 20.71 \\
\hline Labetalol & 73 & 52.14 \\
\hline Nifedipine & 5 & 3.57 \\
\hline $\begin{array}{l}\text { More than one } \\
\text { antihypertensive }\end{array}$ & 33 & 23.57 \\
\hline
\end{tabular}

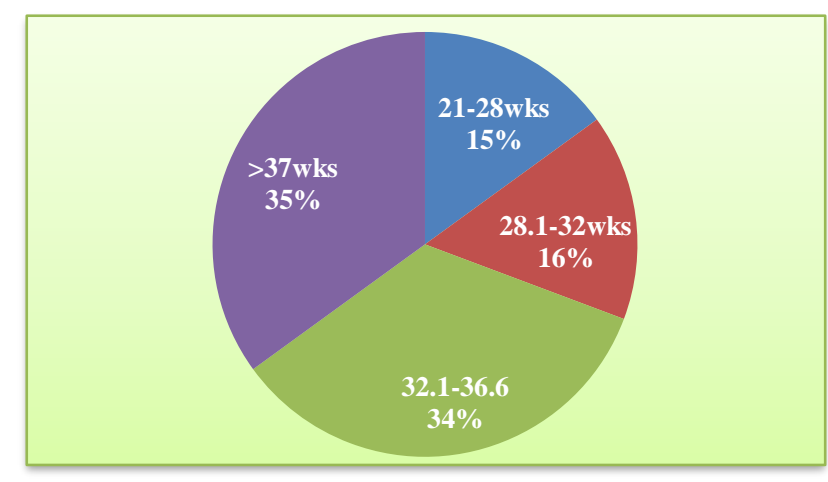

Figure 1: The distribution of patients based on their gestational age at which they were included in the study.

\section{ECG abnormalities}

These forms the main result of the study. 20 patients showed electrocardiographic abnormalities. The most common abnormality was sinus tachycardia and left axis deviation. The other ECG changes were $\mathrm{T}$ wave inversion, left ventricular hypertrophy, low voltage complexes, ST wave inversion and T wave flattening.

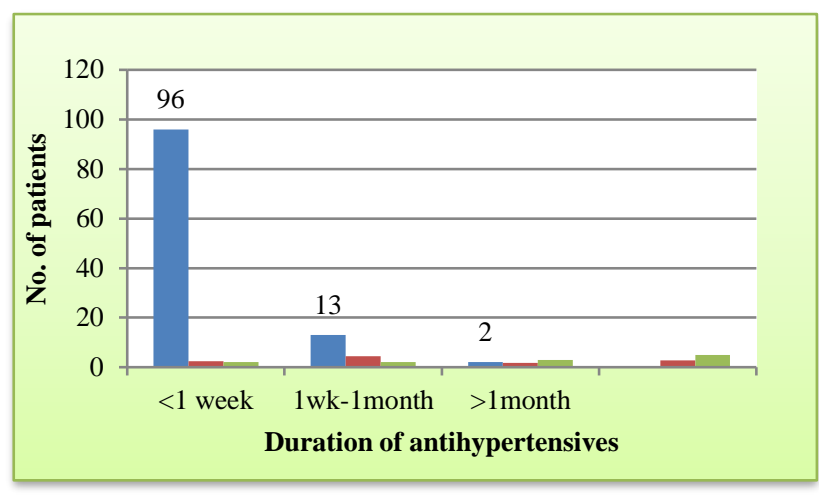

Figure 2: The distribution of duration of antihypertensive therapy.

As shown in Table 3,13.6\% of patients aged less than 30 years and $15.5 \%$ aged more than 30 years showed ECG changes. There appears to be no significant impact of age on the presence of ECG abnormalities. As shown in table 4, a slightly higher percentage $(19.5 \%)$ of multigravidas had ECG changes when compared to primigravidae. 
However, this difference was not significant. As seen in table 4 , while around $15 \%$ of patients above 28 weeks of gestation had ECG changes, only 2 patients had ECG changes below 28 weeks of gestation. There was no statistical difference in the rates of ECG changes among the gestational age groups. ECG changes were present in $17.2 \%$ of patients who were on no antihypertensive therapy. While $15 \%$ of those on labetalol and $20 \%$ of those who were on nifedipine showed ECG changes, $9 \%$ of those who were on multiple antihypertensives showed ECG changes. There was no statistically discernible difference between the rates of ECG changes between those who were on antihypertensives and those without.

Table 3: The distribution of ECG changes tabulated against maternal age, parity status, gestational age and antihypertensive usage.

\begin{tabular}{|c|c|c|c|c|}
\hline & ECG changes present & No ECG changes & Total & $P$ value \\
\hline \multicolumn{5}{|l|}{ Age } \\
\hline$<30$ & $13(13.6 \%)$ & $82(86.4 \%)$ & 95 & \multirow[b]{2}{*}{0.7987} \\
\hline$>30$ & $7(15.5 \%)$ & $38(84.5 \%)$ & 45 & \\
\hline \multicolumn{5}{|c|}{ Parity status } \\
\hline Primi & $9(12.5 \%)$ & $63(87.5 \%)$ & 72 & \multirow[b]{2}{*}{0.6293} \\
\hline Multi & $11(19.1 \%)$ & $55(80.9 \%)$ & 68 & \\
\hline \multicolumn{5}{|c|}{ Gestational age } \\
\hline$<28 w k s$ & $2(9.50 \%)$ & $19(90.5 \%)$ & 21 & \multirow[b]{2}{*}{0.7379} \\
\hline$>28 w k s$ & $18(15.10 \%)$ & $101(84.9 \%)$ & 119 & \\
\hline \multicolumn{5}{|c|}{ Antihypertensive usage } \\
\hline None & $5(17.2 \%)$ & $24(82.8 \%)$ & 29 & \\
\hline Labetalol & $11(15.06 \%)$ & $62(84.94 \%)$ & 73 & 0.769 \\
\hline Nifedipine & $1(20 \%)$ & $4(80 \%)$ & 5 & 1.0 \\
\hline Multiple & $3(9.09 \%)$ & $30(90.91 \%)$ & 33 & 0.456 \\
\hline
\end{tabular}

All the patients who had ECG abnormalities were evaluated by a cardiologist. 3 patients were advised a $2 \mathrm{D}$ echocardiography, and there were no major abnormalities detected. All patients with ECG abnormalities were informed about the possible need for screening for future cardiovascular risk.

\section{DISCUSSION}

As per the National eclampsia registry, it is estimated that almost 72000 women die of preeclampsia and eclampsia related problems. While the incidence in India is approximately $10 \%$, the global estimates are similar. ${ }^{1}$ It is also well known that cardiovascular disease accounts for approximately $40 \%$ of all the mortalities in the world. ${ }^{2}$ Recent evidence shows that these two conditions may form a continuum.

\section{Long term effects of preelampsia}

Middle aged women in UK were investigated for cardiovascular disease risk with respect to history of hypertension in pregnancy by Canoy et al. It was determined that $26 \%$ of women diagnosed with cardiovascular disease had a history of hypertension in pregnancy. Of these around $27 \%$ had been treated for the same at that time. ${ }^{3}$ Garovic et al studied the association between hypertension in pregnancy and future cardiovascular disease in around 4500 patients. It was found that women with a history of hypertension in pregnancy were at higher risks for a subsequent diagnosis of hypertension, CHD, and stroke. ${ }^{4}$ McDonald et al assessed various cardiovascular factors and parameters of severity and contrasted these among women with a past history of preeclampsia and those without. They concluded that those with remote history of preeclampsia had a higher incidence of chronic hypertension and cardiovascular disease risk. ${ }^{5}$ A meta-analysis by Bellamy has also suggested a three-fold rise in future chronic hypertension and almost a doubling in the risk of thromboembolism, stroke and ischemic heart disease among those with history of preeclampsia. ${ }^{6}$ In the preeclampsia risk evaluation study by Drost et al it was determined that electrocardiographic parameters can be used as a proxy indicator for screening for cardiovascular disease in young women after eclampsia, especially when they continue to be hypertensive. ${ }^{7}$ Since it has now become clear that the occurrence of preeclampsia doubles the risk for subsequent cardiac events, institutions like the American Heart Association have suggested that occurrence of preeclampsia be used as a risk stratifying tool for future cardiovascular risks in women. ${ }^{8}$ However, little data on the future cardiovascular risks of preeclampsia exist in India. ${ }^{1}$

\section{Why ECG in preeclampsia}

Murphy et al conducted a study to determine the effect of preeclampsia on ECG parameters. They concluded that while examining the relation between preeclampsia and 
cardiovascular disease, identification of ECG changes provide an easy, unique and early opportunity for identification and screening for cardiovascular issues, much before other factors become obvious. ${ }^{9}$ Angeli et al studied 221 nulliparous healthy women with singleton pregnancies. They tested various clinical and demographic variables as predictors of future preeclampsia and attempted to delineate the role of ECG. They concluded that simple visual inspection of conventional ECG adds in as a rapid and effective risk screening for hypertensive disorders. ${ }^{10}$ In a study by Melchiorre et al, the significance of asymptomatic left ventricular impairment with acute preeclampsia was studied. A $40 \%$ increased risk of hypertension and $56 \%$ risk of left ventricular dysfunction was found among patients with preeclampsia, as determined by ECG changes at postpartum period, at 1 year and 2 years postpartum. ${ }^{11}$ Hence, from the above, the possible utility of conventional ECG in preeclampsia is clear.

\section{The Indian context}

ECG is a simple, cost-effective and widely available investigation. The Indian obstetrician is well aware that a majority of patients have their first contact with a medical practitioner during pregnancy, and may not have one till some other specific medical disorder arises. While a lot of emphasis is being given on the early identification, optimum management, reduction of morbidity and prevention of mortality related to preeclampsia /eclampsia, very little emphasis is being given to the long-term sequel of this condition. A PubMed search with keywords "preeclampsia electrocardiography India" yielded no results.

\section{ECG abnormalities in preeclamptics}

our findings and other findings in an otherwise healthy (non-pregnant) young population, the rates of ECG changes are reported to be around 5\%. ${ }^{12}$ Population studies have shown wide ranges in the rates of ECG abnormalities among otherwise healthy women, mainly owing age related changes. ${ }^{13}$ Present study found ECG changes in 20 patients. In other words, the rate of ECG changes among pregnancies with preeclampsia was $14.2 \%$.

Very few studies of ECGs in relation to pregnancy have been conducted in India. Sunita et al and Revathi et al have documented the patterns of ECG changes in otherwise normal pregnancies, and had found that ECG changes were more common among pregnant women than in non-pregnant women. They had also recommended that these ECG changes need to be investigated in further detail in relation to systemic problems. ${ }^{14,15}$

We found 7 patients (5\%) with sinus tachycardia. The study by Parthasarathy et al, also found a 5\% rate of sinus tachycardia. However, that study was among healthy pregnant women. ${ }^{16} \mathrm{We}$ found $4.2 \%$ of patients with left axis deviation. Though left axis deviation is frequently dismissed as a physiological change in pregnancy, Hoogsteder et al have shown that $3 \%$ of patients continue to have ECG abnormalities late after postpartum period also. Those with ECG changes had a higher recurrence of preeclampsia in subsequent pregnancy. ${ }^{17}$ We found one patient with features of left ventricular hypertrophy. In a comparative study done by Zanganeh et al, ECG was used as a screening tool for left ventricular hypertrophy among pregnant women. It was confirmed that left ventricular hypertrophy was higher among hypertensive pregnant women and ECG was an effective screening tool for the same. ${ }^{18} \mathrm{We}$ found ST segment abnormalities in 5 patients (of which 3 were $\mathrm{T}$ wave inversion, one with ST segment inversion and one with $\mathrm{t}$ wave flattening). Parthasarathy et al found ST changes in 4 patients. ${ }^{16}$ Revathi et al have also observed very few $\mathrm{T}$ wave inversions in their study. ${ }^{15}$ Though it did not reach statistical significance, we found higher rate of ECG changes among those in third trimester (15\%) compared to those in second trimester $(9 \%)$. Melchiorre noticed a higher rate in preterm preeclamptic women, and also stated that among those with persistent left ventricular dysfunction, the risk of developing hypertension within 2 years was significantly more. ${ }^{11}$

We found higher rate of ECG changes in those belonging to higher age group, higher birth order and those on antihypertensives. However, the difference in the rates did not achieve statistical significance. Zhao et al attempted to use ECG changes as a predictor for pregnancy outcomes in older pregnant women. In their study, it was determined that women more than 35 years with ECG changes had a much higher rate of fetal loss, prematurity and low birth weight. ${ }^{19}$

Rafaelli et al analyzed ECGs in hypertensive pregnant women and found that significant changes in QT, QTc and QTd interval along with changes in ventricular repolarization were observed among hypertensive women. $^{20}$ Inci et al also studied ECG among preeclamptics and demonstrated that the duration of atrial electromechanical delay and $\mathrm{P}$ wave dispersion $(\mathrm{Pd})$ was more prolonged in hypertensive pregnant women. ${ }^{21}$ Such specific parameters such as QTc and Pd, though not part of our study, definitely need to be looked into in future studies.

\section{ECG abnormalities among preeclamptics and future cardiovascular risk}

Kirbas et also found that changes in $\mathrm{P}$ wave duration and dispersions were higher in preeclamptic women, supporting the hypothesis about future cardiovascular morbidity. ${ }^{22}$ Hoogsteder et al studied ECG changes among hypertensive pregnant women and followed up the presence or severity of preeclampsia in the next pregnancy. They found that those who developed preeclampsia earlier in the index pregnancy or those who 
had recurrent preeclampsia in the subsequent pregnancy; had higher rate of ECG findings compared to those who had later onset of preeclampsia in the index pregnancy or those who had uneventful subsequent pregnancy. ${ }^{19}$

\section{CONCLUSION}

To conclude, ECG abnormalities are seen in $14.2 \%$ of preeclamptic women. ECG abnormalities in preeclamptic women studied had no relation to the maternal age, gestational age; parity and use of antihypertensives.

With not just the immediate pregnancy outcome in mind, but the future cardiovascular (and hence overall) health of the lady in mind, performance of an ECG in pregnancy with preeclampsia may be a first step, and may improve the holistic nature of approach of obstetricians towards patients. Measurement of abnormalities including specific parameters in the ECG; follow up of patients to determine whether ECG abnormalities persist long after completion of pregnancies appear to be promising areas for future studies. Before recommending that every preeclamptic patient undergo an ECG, further studies and deliberation is required.

\section{ACKNOWLEDGMENTS}

Author would like to thanks Dr. AS Gupta, Dr. AR Chauhan, Dr. NM Mayadeo, Dr. MN Satia and Dr. PY Samant are acknowledged for allowing patient recruitment from respective units; and their support and encouragement.

Funding: No funding sources

Conflict of interest: None declared

Ethical approval: The study was approved by the Institutional Ethics Committee

\section{REFERENCES}

1. Gupte S, Wagh G. Preeclampsia-eclampsia. J Obstet Gynaecol India. 2014;64(1):4-13.

2. Epstein JA. Epidemiology of Cardiovascular disease. In Longo LD, Kasper DL, JamesonJL, Fauci AS, Hauser SL, Loscalzo J, eds. Harrison's Princiles of internal medicine. 18th ed. Mc Graw Hill.

3. Canoy D, Cairns BJ, Balkwill A, Wright FL, Khalil $\mathrm{A}$, Beral $\mathrm{V}$ et al. Hypertension in pregnancy and risk of coronary heart disease and stroke: A prospective study in a large UK cohort. Int $\mathbf{J}$ Cardiol. 2016;222:1012-8

4. Garovic VD, Bailey KR, Boerwinkle E, Hunt SC, Weder AB, Curb D et al. Hypertension in pregnancy as a risk factor for cardiovascular disease later in life. J Hypertens. 2010;28(4):826-33.

5. McDonald SD, Ray J, Teo K, Jung H, Salehian O, Yusuf $\mathrm{S}$ et al. Measures of cardiovascular risk and subclinical atherosclerosis in a cohort of women with a remote history of preeclampsia. Atherosclerosis. 2013;229(1):234-9.
6. Bellamy L, Casas J-P, Hingorani AD, Williams DJ. Pre-eclampsia and risk of cardiovascular disease and cancer in later life: systematic review and metaanalysis. BMJ. 2007;335(7627):974.

7. Drost JT, van der Schouw YT, Ottervanger JP, van Eyck J, de Boer M-J, Maas AHEM. Electrocardiographic parameters in women ten years post-early preeclampsia. Maturitas. 2012;73(2):14851.

8. Mosca L, Benjamin EJ, Berra K, Bezanson JL, Dolor RJ, Lloyd-Jones DM. Effectiveness-Based Guidelines for the Prevention of Cardiovascular Disease in Women-2011 Update. Circulation. 2011;123:1243-1262.

9. Murphy MSQ, Seaborn GEJ, Redfearn DP, Smith GN. Reduced Heart Rate Variability and Altered Cardiac Conduction after Pre-Eclampsia. PLoS One. 2015;10(9):e0138664.

10. Angeli F, Angeli E, D'antonio A, Poltronieri C, Ambrosio G. Risk Prediction Models for Hypertensive Disorders of Pregnancy: Role of 12Lead Electrocardiography. Naissensis. 2016;33(2):79-90.

11. Melchiorre K, Sutherland GR, Liberati M, Thilaganathan B. Preeclampsia is associated with persistent postpartum cardiovascular impairment. Hypertens. 2011;58(4):709-15.

12. Pelliccia A, Culasso F, Di Paolo FM, Accettura D, Cantore R, Castagna W, et al. Prevalence of abnormal electrocardiograms in a large, unselected population undergoing pre-participation cardiovascular screening. Eur Heart J. 2007;28(16):2006-10.

13. Hingorani P, Natekar M, Deshmukh S, Karnad DR, Kothari S, Narula D et al. Morphological abnormalities in baseline ECGs in healthy normal volunteers participating in phase I studies. Indian $\mathbf{J}$ Med Res. 2012;135:322-30.

14. Sunita M, Chandrasekharappa S, Brid SV. Electrocradiographic QRS Axis, Q Wave and Twave changes in 2nd and 3rd trimester of normal pregnancy. J Clin Diag Res. 2014;8(9):BC17-21.

15. Revathi M, SujathaV, Sunitha K, Venkatachalam M. A Comparative Study of electrocardiographic changes in pregnant and non-pregnant women. IOSR J Dent Med Sci. 2015;14(7):2279-861.

16. Parthasarathy S, Sripriya R, Krishnaveni N. A study of the electrocardiographic changes in normal pregnant women. RJPBCS. 6(3):975-8585.

17. Hoogsteder PH, Krüse AJ, Sep SJ, Dassen WR, Gorgels AP, Peeters L. Electrocardiographic findings in women with a recent history of pre-eclampsia. Acta Obstet Gynecol Scand. 2012;91(3):372-8.

18. Zangeneh M, Veisi F, Malekkhosravi S, Rezavand N, Nankali A, Rezaei M et al. Electrocardiographic changes in healthy and pre eclamptic pregnant women. J Kermanshah Univ Med Sci. 2012;16(4):339-44.

19. Zhao XQ, Wang CG, Song YX, Jiao H. Zhongguo Ying Yong Sheng Li Xue Za Zhi. The relationship of 
ECG and pregnancy outcome of older pregnant woman in late pregnancy. 2014;30(1):44-7.

20. Raffaelli R, Prioli MA, Parissone F, Prati D, Carli M, Bergamini $\mathrm{C}$ et al. Pre-eclampsia: evidence of altered ventricular repolarization by standard ECG parameters and QT dispersion. Hypertens Res. 2014;37(11):984-8.

21. Inci S, Nar G, Aksan G, Sipahioglu H, Soylu K, Dogan A. P-Wave Dispersion and Atrial Electromechanical Delay in patients with preeclampsia. Med Princ Pract. 2015;24(6):515-21.
22. Kirbas O, Biberoglu EH, Kirbas A, Daglar HK, Kurmus O, Uygur D, et al. P-wave duration changes and dispersion in preeclampsia. Eur J Obstet Gynecol Reprod Biol. 2014;183(2):141-5.

Cite this article as: Desai D, Prasad MS.

Electrocardiographic profile of patients with hypertensive disorders in pregnancy. Int J Reprod Contracept Obstet Gynecol 2017;6:2569-74. 